\title{
Approach to urinary incontinence in the elderly in primary care: a mini review
}

\begin{abstract}
Urinary incontinence is a serious health problem increasing in frequency with age. It is not a natural consequence of aging it is a pathological condition and can be substantially improved even if it cannot be cured. The biggest problem in this regard is that patients do not adequately express these complaints and do not receive medical treatment. For this reason, primary care physicians have important duties in this regard. Clinicians should question the patients especially in terms of UI in primary care even if they apply with another complaint. Basic evaluation for etiology should be done after the diagnosis of IU, lifestyle changes and behavior therapies should be applied at this stage, other than urgent and specific treatment requirements. After a minimum of 3 months of treatment, medical treatments may be given where deemed necessary, or the patients may be referred to secondary care units.
\end{abstract}

Volume I Issue 6 - 2017

\author{
Sebahat Gücük,' Adnan Gücük² \\ 'Deparment of Family Medicine, University of Abant İzzet Baysal, \\ Turkey \\ ${ }^{2}$ Department of Urology, University, University of Abant İzzet \\ Baysal,Turkey
}

Correspondence: Sebahat Gücük, Department of Family Medicine, University of Abant İzzet Baysal,Turkey, Tel 09505674 81 92, Email sebahatgu@yahoo.com

Received: July 17, 2017 | Published: August 02, 2017

Keywords: urinary incontinence, elderly, primary care

\begin{abstract}
Abbreviations: UI, urinary incontinence; WHO, world health organization; PMR, post-micturition residue

\section{Introduction}

Irrespective of the volume, any kind of involuntary urination is defined as urinary incontinence. ${ }^{1}$ Urinary incontinence is emerging as an important problem increasing in frequency with aging. Even if it seems to be a more common problem in the elderly, it is not a natural consequence of aging and it shows a pathological condition at all ages. ${ }^{2}$ Since it is a social problem that is not usually mentioned by the elderly patient, it is not well recognized and addressed by the clinicians. ${ }^{3}$ However, while the incidence rate in the population over 60 years is $15-30 \%$, this rate reaches $60-70 \%$ in the elderly in nursing homes. ${ }^{4}$ Detection and proper treatment or guidance of this problem, which is so frequent and can be cured or reduced in frequency with supportive or specific treatments, by primary care physicians is the most important step in the solution of this problem.
\end{abstract}

Although urinary incontinence (UI) is seen 1.5-2 times more in women up to 80 years and after that age it is observed in both sexes in similar rate ${ }^{5}$ Urinary incontinence is an important problem that leads to hygiene loss, pressure sores, sleep disturbance, sexual dysfunction, depression, social isolation, increased risk of fracture, impaired quality of life, and increase in the risk of being placed in a nursing home. ${ }^{6,7}$ Many patients limit their social activity and this causes them to go away from their environment. ${ }^{8}$ In addition, economic cost is higher in the United States than the money spent on dialysis and coronary bypass surgery and is gradually increasing. The total cost of incontinence, especially in nursing homes, reaches significant figures. ${ }^{9}$ Why this problem, which has such negative effects on the elderly health and quality of life, and which is a serious cost to the countries, is not being treated adequately or cannot be detected? This is partly because elderly people see this problem as a natural consequence of aging, and partly because they do not raise this problem due to feeling of ashamed and concerns such as need for surgical treatment or they will not be treated etc. Many doctors are reluctant to scrutinize this issue, do not adequately question it, or do not have sufficient information of the treatment. However, it should be known that aging alone does not lead to incontinence and can be successfully cured. ${ }^{10}$ For these reasons, this matter should be made known, questioned and treatment be provided. The purpose of this article is to help realize these patients in primary care and give proper treatment or guidance.

As a result of a number of physiological changes that occur in the urinary system with aging, incontinence development gets easy. These physiological changes:

a. Prostate hypertrophy in men

b. Tendency of decrease in urethral pressure with age

c. Atrophic changes caused by menopause in women, decrease in connective tissue surrounding the urethra

d. Decrease in detrusor contractility

e. Detrusor over activity

Increase in post-micturition residue and deterioration of diurnal rhythm of antidiuretic hormone ${ }^{4}$ Apart from these, there are many factors other than genitourinary system which makes the development of urinary incontinence easier. Among these, the drugs used for the chronic diseases are the most important. In addition, diabetes mellitus, heart failure, cerebrovascular diseases, some neurological and metabolic disorders cause incontinence or facilitate this. ${ }^{11-13}$

\section{Clinical evaluation}

Although UI is a frequent problem in geriatric patients, it is much less common for the patients to apply to a doctor with this complaint. Patients often do not express these complaints unless they affect their lives much. In Norton and ark studies $25-30 \%$ of women with UI complaint waited more than 5 years to ask for medical support. Although almost half of them had complaints seriously limiting their lives they did not apply to doctor because they were embarrassed. For this reason, clinicians should question patients in terms of UI especially in primary care even if they are admitted with another complaint. 
World Health Organization has identified UI as one of the four major problems of the elderly. WHO has developed a screening test regarding this, with the test which can also be done by a nonphysician personnel in 10-minute, 4 major problems including depression, dementia, fall, and UI can be screened. ${ }^{14}$ Two questions questioning urinary incontinence in this questionnaire:

A. Have you ever had urinary incontinence or got wet in the past year?

B. Did you have urine leakage in the last week?

\section{Positive evaluation: The answer to both questions is yes}

The answer yes to both questions is accepted as positive and reveals the need for detailed evaluation of the patient's UI. After the detection of this problem, how much the patient is disturbed by this symptom and treatment request are revealed. The first goal of evaluating patients with urinary incontinence is to identify whether the condition is temporary or permanent and to plan treatment. The secondary purpose is to determine the need for more specific evaluation of the patient and if necessary referral for specialist care. ${ }^{15}$

When incontinence is detected it is important to determine whether it is due to transient causes. Transient causes of UI directly cause incontinence or they are causes that may aggravate existing incontinence and may be remembered with DIAPPERS initials These are transient causes reminiscent with the initials of Delirium, infection, atrophic vaginitis, pharmaceutical, psychological, excess fluids, restricted mobility, stool impaction initials. ${ }^{5}$ If incontinence persists after these transient causes have been ruled out and conditions have been improved, permanent causes should come to mind. The types of incontinence caused by these persistent causes include functional continence, stress incontinence, urge incontinence, mixed and overflow incontinence. While mixed incontinence is observed in more than half of women, urge incontinence type is more common in men.

With a detailed anamnesis, frequency of incontinence, severity and its impact on quality of life should be questioned. Gynecological history, past surgeries, pelvic trauma, radiotherapy treatment, some neurological diseases, used medications should be questioned. The patients with incontinence should be questioned on the relation of incontinence to coughing, sneezing, weight lifting, bending and lifting and exercise. Whether s/he can reach the toilet in time or not when feeling of urge to urinate occurs is important in terms of showing both the mobility and the severity of the complaint.

Bladder diary is used for initial evaluation in patients with incontinence. While 3-day evaluation is more effective, the amount of intake output fluid in 24 hours and the time schedule are often sufficient at the beginning. It is known that nocturia detected in bladder diary contributes to the reduction of incontinence by controlling only the fluid intake habits. ${ }^{16}$

In physical examination fecal impaction gives important information about the causes of atrophic vaginitis, enlarged prostate. The presence of cystocele detection of stress incontinence, and pathologies such as urethral caruncle etc. may require referral to a relevant specialist.

Post-micturition residue (PMR) is a value that can also be easily checked in primary care and can tell us about the cause and severity of the incontinence. PMR is recommended to be measured in the patients with severe contraception, in complex neurological disorders, organ prolapse, and in the patients using anticholinergics. It can be easily measured with US, the amount increases with aging and further evaluation may be required if it is more than $100-150 \mathrm{~m}$.

\section{Treatment}

If incontinence in patients is not a sign of an important and urgent problem, initiation of treatment in primary care both increases efficiency and reduces cost. UI therapy is planned according to the severity of the disease, it is recommended that the least invasive and least risky method should be the first option for the patient with incontinence. ${ }^{17}$ After comorbidities, drugs and other facilitating factors are considered, evaluation of lifestyle changes, behavioral treatment, and of the chronic disease drugs taken by the patient both reduces the patient's complaints and contributes to faster and more effective treatment when referred to the secondary care.

It is quite effective to give lifestyle changes in primary care. In obese patients, weight control alone can eliminate stress incontinence. ${ }^{18}$ Constipation, limiting consumption of caffeinated beverages, sodas and alcohol can reduce incontinence. ${ }^{19}$ Regulation of the amount and timing of fluid intake, limiting activities that affect the pelvic floor, preventing constipation contribute to incontinence treatment as basic lifestyle changes.

When we look at behavioral treatments, bladder training and pelvic floor muscles exercises are frequently used in combination with urge, stress and mixed incontinence. The main purpose of bladder training is to reduce the number of urination and to control urination. Knowing the starting status with bladder diary contributes to this. When patients feel urgency to urinate, they want to go to the toilet immediately, run and bladder also accompanies that. Incontinence is inevitable at that moment. However, need for urgent urination comes like a wave, suddenly arrives, gets stronger, reaches maximum, and gradually disappears. Thus, when feeling of urge comes, preserving the position and contracting pelvic floor allows the urinary incontinence to cease after 10-15 seconds of hard period and allows the patient to urinate in the toilet without incontinence. Considering that these patients are elder, complications such as fall, fractures, etc. caused by the need to move fast will not occur. It takes time for the patient to learn to gradually delay the complaint of urge, yet it is a permanent and complicated treatment option ${ }^{20}$ Another behavioral treatment method is to help patients who cannot have bladder training due to cognitive impairment go to the toilet before uncontrollable feeling of urge starts.

Here again bladder diaries provide us with the necessary information. The functional bladder capacity, which we can set as the maximum urine volume per day, tells us how often the patient should urinate. The objective here is to adapt the patient to his or her functional bladder capacity and to ensure that $\mathrm{s} / \mathrm{he}$ urinates as often as needed before the feeling of urge to pee. Pelvic floor training is also an easy method that can be preferred in primary care and that gives positive results for the patients when applied regularly. The aim here is to make patient learn how to increase intraurethral resistance using periurethral muscles. Details of these exercises can be provided by telling the patient and, if necessary, by giving initial training in the presence of a physiotherapist. These exercises aim to activate the slow fibers of the pelvic floor muscles and to increase their resistance. ${ }^{21}$

Medical treatment should be started after lifestyle changes and behavior therapies of up to 3 months are applied and when there is no 
benefit. At least this 3-month first-line treatment can be started easily and without worrying in primary care. In cases where these treatments are inadequate, starting medical treatments on the patients requires assessment at the level of expertise. However, -medical treatment can be given carefully by primary care physicians who are adequately interested and experienced in this regard. Among these treatments duloxetine selective serotonin used for stress incontinence has become reuptake inhibitor and has been approved. ${ }^{22}$ Antimuscarinic agents are used very effectively in urge incontinence. These drugs increase bladder capacity, and block the release of basal acetyl cholines during bladder filling. Many agents such as Oxybutynin, darifenacin, propiverine, fesoterodine, etc. are used. ${ }^{13}$ They should be used in elderly patients considering chronic diseases and the conditions where the drug is contraindicated. It is necessary to wait 4-6 weeks for their effects. They may lead to problems such as dry mouth, constipation, blurred vision, tachycardia, dizziness. They can make it difficult for the patients to urinate and may increase residual urine. For this reason, attention should be paid to these issues in follow-ups.

\section{Conclusion}

As a result, UI is one of the most important problems seen in the elderly. Especially in primary care even if the patients themselves do not apply with this complaint, questioning this patients in this respect must be the beginning in the detection of the problem. If the evaluation made afterwards according to the cause of the incontinence does not reveal a specific situation, lifestyle changes and behavior therapies should be applied in the first place. In this case, the patients who do not get effective results can preferably be referred to secondary care or the option of medical treatment that can be applied by an experienced and well-informed primary care physician in this area can be used.

\section{Acknowledgements}

None.

\section{Conflict of interest}

There is no conflict of interest in composing this manuscript.

\section{References}

1. Abrams P, Cardozo L, Fall M, et al. The standardisation of terminology of lower urinary tract function: Report from the of the International Standardisation Sub-Committee Continence Society. Neurourol Urodynam. 2002;21(2):167-178.

2. Park WH. Urinary Incontinence and Physician's Attitude. J Korean Med Sci. 2013;28(11):1559-1560.

3. Padros J, Peris T, Salva A, et al. Evaluation of a urinary incontinence unit for community-dwelling older adults in Barcelona: Implementation and improvement of the perceived impact on daily life, frequency and severity of urinary incontinence. Z Gerontol Geriatr. 2008;41(4):291-217.
4. Akın S. Yaşlılarda Üriner İnkontinans. Kontinans ve Nöroüroloji Bülteni. 2015;2:49-54.

5. Riemsma R, Hagen $\mathrm{S}$, Norton $\mathrm{C}$, et al. Can incontinence be cured? A systematic review of cure rates. BMC Med. 2017;15(1):63.

6. Goepel M, Hoffmann JA, Piro M, et al. Prevalence and physician awareness of symptoms of urinary bladder dysfunction. Eur Urol. 2002;41(3):234-239.

7. Elbadawi A, Yalla SV, Resnick NM. Structural Basis of Geriatric Voiding Dysfunction .1. Methods of a Prospective Ultrastructural Urodynamic Study and an Overview of the Findings. J Urology. 1993;150(5):1650-1656.

8. Mitteness LS. Knowledge and Beliefs About Urinary-Incontinence in Adulthood and Old-Age. J Am Geriatr Soc. 1990;38(3):374-378.

9. Farage MA, Miller KW, Berardesca E, et al. Psychosocial and societal burden of incontinence in the aged population: a review. Arch Gynecol Obste. 2008;277(4):285-290.

10. Wilson L, Brown JS, Shin GP, et al. Annual direct cost of urinary incontinence. Obstet Gynecol. 2001;98(3):398-406.

11. Markland AD, Vaughan CP, Johnson TM, et al. Incontinence. Med Clin North Am. 2011;95(3):539-554.

12. DuBeau CE. Beyond the bladder: Management of urinary incontinence in older women. Clin Obstet Gynecol. 2007;50(3):720-734.

13. Catherine ED. Urinary incontinence. Informa Geriatric Review Syllabus, New York, USA; 2010;231-242.

14. Visser E, Dekker JH, Vermeulen KM, et al. The effect of systematic screening of older women for urinary incontinence on treatment uptake: The URINO trial. Maturitas. 2013;74(4):334-340.

15. Hunskaar S, Burgio K, Diokno A, et al. Epidemiology and natural history of urinary incontinence in women. Urology. 2003;62(4 Suppl 1):16-23.

16. Culligan PJ, Heit M. Urinary incontinence in women: Evaluation and management. Am Fam Physician. 2000;62(11):2433-2444.

17. Christofi N, Hextall A. An evidence-based approach to lifestyle interventions in urogynaecology. Menopause Int. 2007;13(4):154-158.

18. Subak LL, Wing R, West DS, et al. Weight Loss to Treat Urinary Incontinence in Overweight and Obese Women. New Engl $\mathrm{J}$ Med. 2009;360(5):481-490.

19. Nygaard I. Idiopathic Urgency Urinary Incontinence. New Engl J Med. 2010;363(12):1156-1162.

20. Liao YM, Dougherty MC, Liou YS, et al. Pelvic floor muscle training effect on urinary incontinence knowledge, attitudes, and severity: An experimental study. Int J Nurs Stud. 2006;43(1):29-37.

21. Smith HJ, Morkved S, Fairbrother KA, et al. Pelvic floor muscle training for prevention and treatment of urinary and faecal incontinence in antenatal and postnatal women. Cochrane Database Syst Rev. 2008;8(4).

22. Sweeney DD, Chancellor MB. Treatment of stress urinary incontinence with duloxetine hydrochloride. Rev Urol. 2005;7(2):81-86. 